\title{
Suboptimal use of neoadjuvant chemotherapy in radical cystectomy patients: A population-based study
}

\author{
Jonas Schiffmann, MD;,1,2 Maxine Sun; Giorgio Gandaglia, MD;,2, Zhe Tian; ${ }^{2}$ Ioana Popa, MD; ${ }^{2}$ \\ Alessandro Larcher, MD, ${ }^{2,4}$ Malek Meskawi, MD; ${ }^{2}$ Alberto Briganti, MD,; Michael McCormack, MD; ${ }^{5}$ \\ Shahrokh F. Shariat, MD, ${ }^{6}$ Francesco Montorsi, MD, ${ }^{3}$ Markus Graefen, MD; ${ }^{1}$ Fred Saad, MD; ${ }^{7}$ \\ Pierre I Karakiewicz, MD, FRCSC ${ }^{2,7}$
}

'Martini-Clinic, Prostate Cancer Centre, University Medical Centre Hamburg-Eppendorf, Germany; ${ }^{2}$ Cancer Prognostics and Health Outcomes Unit, University of Montreal Health Centre, Montreal, QC, Canada; ${ }^{3}$ Department of Urology, Vita-Salute, San Raffaele University, Milan, Italy; ${ }^{4}$ Division of Oncology, Unit of Urology, URI, IRCCS Ospedale San Raffaele, Milan, Italy; ${ }^{5}$ Department of Surgery, University of Montreal, Montreal, QC, Canada; ' Department of Urology, Medical University of Vienna, Vienna, Austria; 'Department of Urology, University of Montreal, Montreal, QC, Canada

Cite as: Can Urol Assoc J 2016;10(3-4):E82-6. http://dx.doi.org/10.5489/cuai.3292

\section{Abstract}

Introduction: We aimed to assess contemporary rates of neoadjuvant chemotherapy (NC) use.

Methods: We relied on the Surveillance, Epidemiology and End Results (SEER)-Medicare database for non-metastatic, muscle-invasive (T2-T4a) urothelial carcinoma of the urinary bladder (UCUB) patients who underwent radical cystectomy (RC) between 1991 and 2009. Multivariable logistic regression analyses tested predictors of NC use, such as: T-stage, N-stage, year of diagnosis, age at diagnosis, gender, race, use of radiotherapy (RT), marital status, urban status, socioeconomic status, tumour grade, and Charlson comorbidity index $(\mathrm{CCl})$.

Results: Overall, 5207 patients treated with RC were identified. Of those, $332(6.4 \%)$ received $\mathrm{NC}$. The rate of $\mathrm{NC}$ increased over time from $6.1 \%(1991)$ to $15.0 \%(2009)(\mathrm{p}<0.001)$. In multivariable analyses, year of diagnosis (odds ratio [OR]: 4.7; $\mathrm{p}<0.001$ ), lower T-stage (T3 vs. T2: OR: 0.7; $\mathrm{p}=0.003)$, married status (OR: $1.5 ; p=0.006$ ), and younger age at diagnosis ( $\geq 80$ vs. $66-69$ : OR: $0.6 ; p=0.006$ ) were associated with a higher odds of NC; all represented independent predictors of $\mathrm{NC}$ use. Neither race nor $\mathrm{CCl}$ demonstrated statistical significance.

Conclusions: We reported lower than anticipated overall (6.4\%) use of NC. Nonetheless, the rate increased from $6.1 \%$ (1991) to $15.0 \%$ (2009). Older and unmarried individuals were less likely to receive NC. NC rates were higher in T2 UCUB patients. Some of the observed discrepancies, such as lower use in unmarried individuals, may require correction. Better adherence to guidelines should be encouraged and implemented, especially based on the confirmed benefits of NC according to randomized, controlled trials. The study is limited by a retrospective design and limited variables.

\section{Introduction}

American Cancer Society estimates 72570 new cases of bladder cancer (BC) in the U.S. in 2013 and about 15210 deaths from $B C$ within the same year. ${ }^{1}$ Muscle-invasive urothelial carcinoma of the urinary bladder (UCUB) presents $25 \%$ of incident cases. ${ }^{2}$ Radical cystectomy (RC) is the standard of care in non-metastatic, muscle-invasive UCUB patients with adequate performance status. ${ }^{3,4}$ Since improved survival with neoadjuvant chemotherapy (NC) was recorded starting in $2003,{ }^{5-7}$ its administration is recommended by guidelines for patients with clinical stage T2-4a NOMO UCUB. ${ }^{3,4}$ Despite this broad recommendation for use of NC, population-based reports indicate low rates of NC administration in the context of RC, with $5.9 \%$ between 1992 and 2002 and $20.9 \%$ in 2010 in the U.S. ${ }^{8,9}$ Based on this apparent non-adherence to guidelines, we examined the NC rates prior to RC within the Surveillance, Epidemiology and End Results (SEER)-Medicare database focusing on individuals treated between 1991 and 2009.

\section{Methods}

\section{Study source}

The current study relied on the SEER-Medicare-linked database. This database is $98 \%$ complete for case ascertainment. The SEER registries identify $28 \%$ of all incident cancer cases in the U.S. Medicare insures approximately $97 \%$ of all Americans aged $\geq 65$ years. Linkage to the SEER database is complete for approximately $93 \%$ of cases. ${ }^{10}$ 


\section{Study population}

Overall 15080 patients with a primary, non-metastatic, muscle-invasive (T2-T4) UCUB (International Classification of disease for Oncology [ICD-O] site code 67.0, histologic code 8120 or 8130 ), with or without lymph node metastases, diagnosed between January 1991 and December 2009 were abstracted. Patients not enrolled in Medicare parts A or B for a minimum of 12 months prior to their first recorded diagnosis and for six months after diagnosis were not considered. Patients who had health maintenance organization (HMO) enrolment in the year prior to diagnosis or for any period following diagnosis were also excluded. To ensure that all subjects had at least one year of claims from which comorbidities are derived, only those aged $\geq 66$ years old were considered. This resulted in 7337 assessable patients. Additional exclusions comprised those with unknown race $(n=36)$ and unknown marital status $(n=432)$. Furthermore, patients treated with surgery $\geq 6$ months after diagnosis were also not considered in the current study $(n=1185)$. Finally, patients with stages $\mathrm{T} 4 \mathrm{~b}$ or $\mathrm{T} 4$ not otherwise specified were omitted from our analyses, as the current guidelines suggest a different management approach for such individuals $(n=477)$. This resulted in 5207 assessable individuals with T2-T4a, N0 or Nx and N+ patients, who represent potential candidates for NC.

\section{Covariates}

Covariates comprised age at diagnosis, comorbidities (derived using a validated algorithm based on the Charlson comorbidity index $\left.[\mathrm{CCl}]^{11}\right)$, tumour extent (T2, T3, T4a) represented as a consensus state (highest of either clinical or pathological), tumour grade (low-, high-grade), nodal stage $(\mathrm{NO} / \mathrm{Nx}, \mathrm{N}+)$, gender, race (White, other), marital status (married, unmarried), socioeconomic status (SES) (composite variable of income, education, and poverty levels), ${ }^{12}$ year of diagnosis, urban residence status (non-, metropolitan), and radiotherapy (RT).

\section{Statistical analyses}

We compared baseline characteristics between RC patients, who were either administered to NC or not (Table 1). Subsequently, univariable and multivariable logistic regression analyses were performed to identify the clinical and demographic characteristics associated with the use of NC. Means, medians, and interquartile ranges were reported for continuous variables. Frequencies and proportions were reported for categorical variables. The t-test, the MannWhitney test, and chi-square tests were used to compare the statistical significance of differences in means, medians, and proportions, respectively. All statistical tests were performed using R software environment for statistical computing and graphics (Vienna, Austria, version 3.0.1). All tests were twosided, with a significance level set at $p<0.05$.

\section{Results}

\section{Baseline characteristics}

Overall, 5207 patients with non-metastatic, muscle-invasive UCUB who underwent RC were included in the study cohort (Table 1). Mean (median) age at diagnosis was 75.5 (75.0) years. Overall, $332(6.4 \%)$ RC patients were treated with NC vs. 4875 (93.6\%) who were not. Within these groups, statistically significant differences were recorded according to age at diagnosis, marital status, socioeconomic status, tumour stage, rate of organ-confined tumours, tumour grade, and administration of RT (Table 1; all $p<0.05$ ). Specifically, NC patients were younger (median age: 74.0 vs. 75.5 years) and were more frequently married (73.8 vs. $64.9 \%$ ). Additionally, a larger proportion of $\mathrm{NC}$ patients was included in the low SES group (56.9 vs. $49.2 \%$ ). NC patients more often had organ-confined disease (53.3 vs. $45.0 \%$ ). RT was also more frequently delivered in NC patients (20.5 vs. $14.5 \%)$. The rate of NC increased over time from $2.8 \%$ to $10.9 \%$ (Fig. $1 ; \mathrm{p}<0.001)$, where the highest rate was recorded in 2009 $(15.0 \%)$.

\section{Logistic regression models}

In univariable logistic regression analyses predicting the administration of $\mathrm{NC}$, six variables emerged as statistically significant predictors of NC prior to RC. The strongest predictor was the year of diagnosis. Individuals treated and diagnosed between 2006 and 2009 had a higher rate of NC administration than their counterparts treated and diagnosed between 1991 and 1999 (odds ratio [OR]: 4.2 (95\% confidence interval [Cl]: 2.9-6.0; $\mathrm{p}<0.001)$. Married individuals were more likely to receive $\mathrm{NC}$ compared to their unmarried counterparts (OR: 1.5; 95\% Cl: 1.2-2.0; $\mathrm{p}=0.001)$. Lower socioeconomic status was associated with a higher probability of receiving NC (OR: 1.4; 95\% $\mathrm{Cl}: 1.1-1.7 ; p=0.006)$. Higher tumour grade indicated higher odds of $\mathrm{NC}$ administration (OR: 2.1; 95\% Cl: 1.1-3.9; $\mathrm{p}=0.03$ ). Additionally, patients with tumour stage T3 had a significantly lower probability of receiving NC (OR: 0.7; $95 \%$ Cl: $0.5-0.9 ; p=0.003)$. Similarly, patients $\geq 80$ years had a lower probability of being exposed to NC compared to their counterparts between 66 and 69 years (OR: 0.6; 95\% $\mathrm{Cl}: 0.5-0.9 ; \mathrm{p}=0.006)$. Importantly, nodal stage, $\mathrm{CCl}$, and race were not associated to $\mathrm{NC}$ administration (Table 2).

In multivariable logistic regression analyses, four variables emerged as independent predictors of NC administra- 


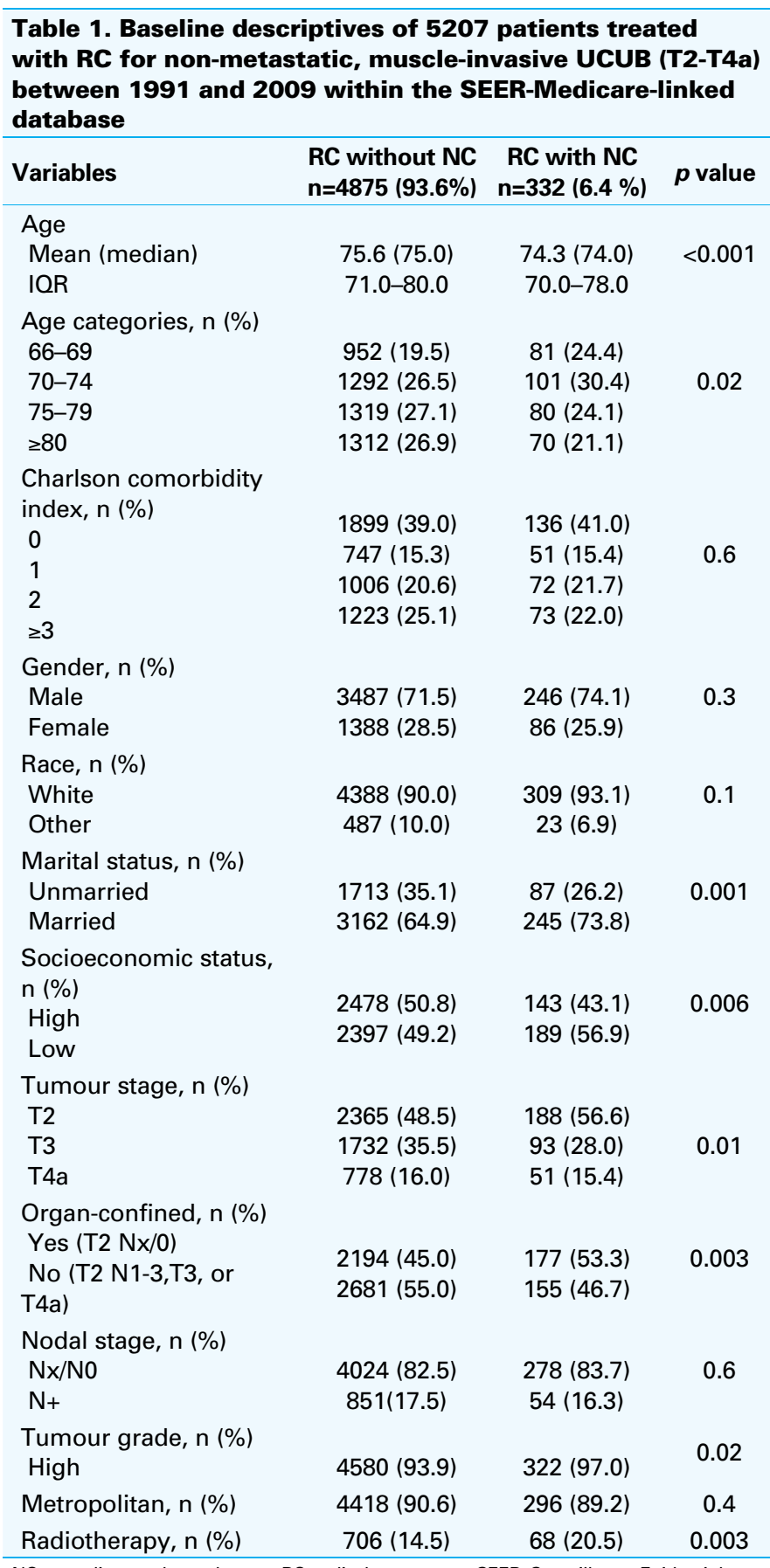

NC: neoadjuvant chemotherapy; RC: radical cystectomy; SEER: Surveillance, Epidemiology and End Results; UCUB: urothelial carcinoma of the urinary bladder.

tion. Patients diagnosed and treated in most recent years had a higher likelihood of receiving NC. Specifically, individuals treated and diagnosed between 2006 and 2009 had a 4.7fold higher rate of $\mathrm{NC}$ administration than their counterparts treated and diagnosed between 1991 and 1999 (OR: 4.7; 95\% Cl: 3.2-7.0; $\mathrm{p}<0.001)$. It is of interest to note that married individuals had 1.5 -fold higher odds of receiving $\mathrm{NC}$, compared to their unmarried counterparts (OR: $1.5 ; 95 \% \mathrm{Cl}$ :

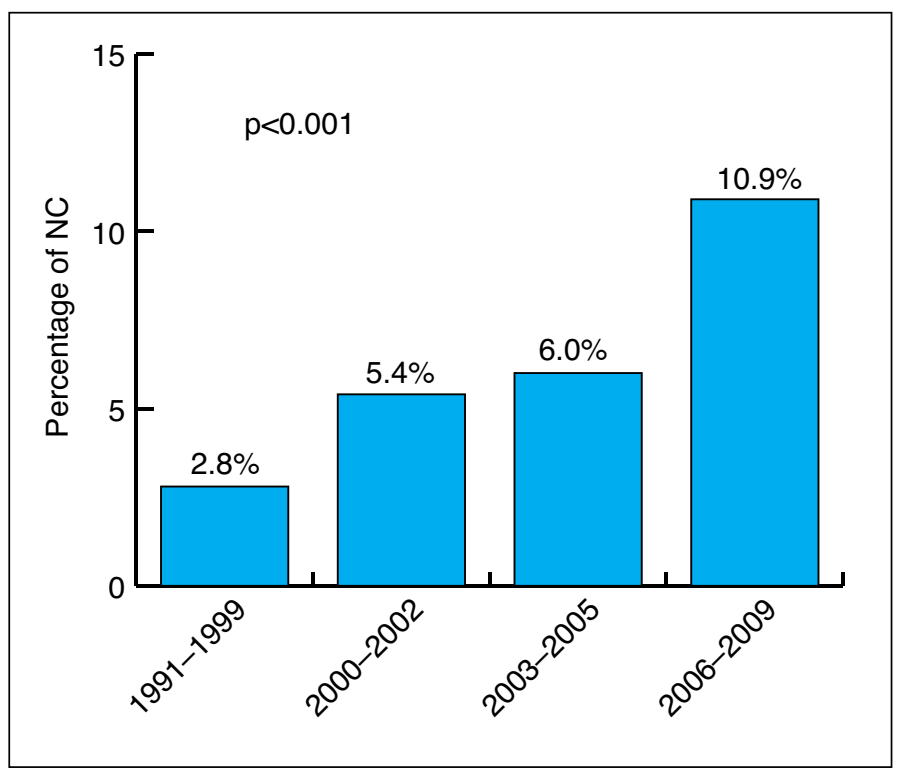

Fig. 1. Rate of neoadjuvant chemotherapy according to year of diagnosis.

1.1-1.9, $\mathrm{p}=0.006$ ). With respect to tumour characteristics, patients with tumour stage T3 had a significantly lower probability of receiving $\mathrm{NC}$ (OR: $0.7 ; 95 \% \mathrm{Cl}$ : $0.5-0.9 ; \mathrm{p}=0.003$ ). It is also of note that advanced age decreased the likelihood of NC administration. Specifically, patients $\geq 80$ years had a $40 \%$ lower probability of being exposed to NC (OR: 0.6; 95\% Cl: 0.4-0.9; $p=0.006$, Table 2).

\section{Discussion}

Our hypothesis stated that the rates of NC administration have increased in most contemporary years. We were able to confirm an overall increase in the rates of NC. However, the absolute rate of $\mathrm{NC}$ use was low during the initial, as well as the final time periods of the study. Specifically, NC rates ranged from $2.8-10.9 \%$ according to time periods (1991-1999 vs. 2000-2002 vs. 2003-2005 vs. 2006-2009), with a peak of $15.0 \%$ in 2009 . These low rates sharply contrast with the National Comprehensive Cancer Network (NCCN) and European Association of Urology (EAU) guidelines that recommend routine use of $\mathrm{NC}$ in individuals with T2-T4a UCUB. ${ }^{3,4}$ The increasing trend is nonetheless explained by increasing dissemination of existing guidelines. This, in turn, may indicate that guidelines result in optimization of patient care.

Several important additional observations also warrant mention. For example, our multivariable models results identified several patient characteristics that represented relative barriers to administration of NC. Advanced patient age limited NC administration rate. This finding is in agreement with an acknowledged relative contraindication to NC for patients with advanced age, especially when cisplatinbased chemotherapy is considered..$^{13}$ However, such limita- 


\begin{tabular}{|c|c|c|c|c|}
\hline \multirow[t]{2}{*}{ Variables } & \multicolumn{2}{|c|}{ Univariable analyses } & \multicolumn{2}{|c|}{$\begin{array}{c}\text { Multivariable } \\
\text { analyses }\end{array}$} \\
\hline & OR (95\% CI) & $p$ value & OR (95\% Cl) & $p$ value \\
\hline \multicolumn{5}{|l|}{ Age at diagnosis } \\
\hline $66-69$ & 1 (ref.) & & 1 (ref.) & \\
\hline $70-74$ & $0.9(0.7-1.3)$ & 0.6 & $1.0(0.7-1.3)$ & 0.8 \\
\hline $75-79$ & $0.7(0.5-1.0)$ & 0.04 & $0.7(0.5-1.0)$ & 0.07 \\
\hline$\geq 80$ & $0.6(0.5-0.9)$ & 0.006 & $0.6(0.4-0.9)$ & 0.006 \\
\hline \multicolumn{5}{|l|}{ Year of diagnosis } \\
\hline 1991-1999 & 1 (ref.) & & 1 (ref.) & \\
\hline 2000-2002 & $2.0(1.3-3.0)$ & 0.001 & $2.2(1.4-3.4)$ & 0.001 \\
\hline 2003-2005 & $2.2(1.5-3.3)$ & $<0.001$ & $2.4(1.6-3.7)$ & $<0.001$ \\
\hline 2006-2009 & $4.2(2.9-6.0)$ & $<0.001$ & $4.7(3.2-7.0)$ & $<0.001$ \\
\hline \multicolumn{5}{|l|}{ Gender } \\
\hline Male & 1 (ref.) & & 1 (ref.) & \\
\hline Female & $0.9(0.7-1.1)$ & 0.3 & $1.1(0.8-1.4)$ & 0.6 \\
\hline \multicolumn{5}{|l|}{ Race } \\
\hline White & 1 (ref.) & & 1 (ref.) & \\
\hline Other & $0.7(0.4-1.0)$ & 0.07 & $0.7(0.5-1.1)$ & 0.1 \\
\hline \multicolumn{5}{|l|}{ Marital status } \\
\hline Unmarried & 1 (ref.) & & 1 (ref.) & \\
\hline Married & $1.5(1.2-2.0)$ & 0.001 & $1.5(1.1-1.9)$ & 0.006 \\
\hline \multicolumn{5}{|l|}{ Population density } \\
\hline Metropolitan & 1 (ref.) & & 1 (ref.) & \\
\hline Non-metropolitan & $1.2(0.8-1.7)$ & 0.4 & $1.1(0.7-1.6)$ & 0.7 \\
\hline \multicolumn{5}{|l|}{$\begin{array}{l}\text { Socioeconomic } \\
\text { status }\end{array}$} \\
\hline High & 1 (ref.) & & 1 (ref.) & \\
\hline Low & $1.4(1.1-1.7)$ & 0.006 & $1.0(0.7-1.2)$ & 0.7 \\
\hline \multicolumn{5}{|l|}{$\begin{array}{l}\text { Charlson } \\
\text { comorbidity index }\end{array}$} \\
\hline 0 & 1 (ref.) & & 1 (ref.) & \\
\hline 1 & $1.0(0.7-1.3)$ & 0.8 & $0.9(0.7-1.3)$ & 0.6 \\
\hline 2 & $1.0(0.7-1.3)$ & 1.0 & $1.0(0.7-1.3)$ & 0.9 \\
\hline$\geq 3$ & $0.8(0.6-1.1)$ & 0.2 & $0.8(0.6-1.0)$ & 0.07 \\
\hline \multicolumn{5}{|l|}{ Tumour grade } \\
\hline Low & 1 (ref.) & & 1 (ref.) & \\
\hline High & $2.1(1.1-3.9)$ & 0.03 & $1.9(0.97-3.5)$ & 0.06 \\
\hline \multicolumn{5}{|l|}{ Tumour stage } \\
\hline $\mathrm{T} 2$ & 1 (ref.) & & 1 (ref.) & \\
\hline T3 & $0.7(0.5-0.9)$ & 0.003 & $0.7(0.5-0.9)$ & 0.003 \\
\hline $\mathrm{T} 4 \mathrm{a}$ & $0.8(0.6-1.1)$ & 0.2 & $0.9(0.7-1.3)$ & 0.6 \\
\hline \multicolumn{5}{|l|}{ Nodal stage } \\
\hline $\mathrm{NO} / \mathrm{Nx}$ & 1 (ref.) & & 1 (ref.) & \\
\hline $\mathrm{N}+$ & $0.9(0.7-1.2)$ & 0.6 & $0.9(0.6-1.2)$ & 0.4 \\
\hline
\end{tabular}

$\mathrm{Cl}$ : confidence interval; NC: neoadjuvant chemotherapy; OR: odds ratio;

RC: radical cystectomy; ref: reference; SEER: Surveillance, Epidemiology and End Results; UCUB: urothelial carcinoma of the urinary bladder.

tion is only relative. Age alone should not be used to exclude patients from this potentially highly beneficial treatment. ${ }^{14,15}$

Other patient characteristics, such as marital status, also represented barriers to NC administration. For example, married individuals were 1.5 -fold more likely to receive NC than their unmarried counterparts. This finding is in agree- ment with several other urologic malignancies, where married status is associated with better access or higher rates of treatment delivery. ${ }^{16,17}$

Discrepancies related to age and/or marital status are important to note. From a clinical standpoint, physicians may choose to pay particular attention to individuals with characteristics that decrease access or patient interest in NC. Age and marital status represent such characteristics.

Additionally, tumour characteristics also represented a statistically significant variable that influenced the rate of $\mathrm{NC}$ administration. For example, patients with tumour stage T3 were $30 \%$ less likely to receive NC. The association between tumour stage and $\mathrm{NC}$ administration rate, where patients with $\mathrm{T} 3$ disease are less likely to receive $\mathrm{NC}$, might be explained by patient and physician concerns related to potential surgical treatment delays if $\mathrm{NC}$ is chosen. ${ }^{18}$ The $\mathrm{NC}$ recommendations hinge on the Grossman et al data, ${ }^{5}$ which included a $60 \%$ majority of T3-4a patients.

Our findings are in agreement with previously published reports, ${ }^{8,9}$ where the rates of NC were also low. Porter et $\mathrm{al}^{8}$ relied on the SEER-Medicare database. In that study, the rate of NC administration within 8719 patients with muscleinvasive UCUB treated by RC between 1992 and 2002 was $5.6 \%$. Relying on the National Cancer Database, Zaid et al ${ }^{9}$ reported on 5692 patients. Those patients had UCUB stage CT2 or higher and underwent RC between 2006 and 2010. In that patient cohort, the rates of NC increased from $7.6 \%$ in 2006 to $20.9 \%$ in 2010 . Similar to our study, Gotto et $\mathrm{al}^{19}$ recorded increased rates of $\mathrm{NC}$ administration over time according to different Canadian centres between 2007 and 2011. Higher rate of NC in the Zaid et al report may relate to age differences between the current populations and theirs. In the latter, the mean age was 66.6 years and the range was 28-90 years. Conversely, the mean age in our study was 75.5 years and ranged from 66-95 years. To the best of our knowledge, no population-based data indicate higher rates than those described in our study and that of Zaid et al. Moreover, we are unaware of population-based European studies reporting on the use of NC.

Despite its strengths, our study is not devoid of limitations. First, its retrospective design limits the quality of the data. Second, population-based studies contain limited numbers of variables. Moreover, the pathological $\mathrm{T}$ and $\mathrm{N}$ stages represent consensus stages, where the highest of either clinical or pathological is included. Third, several important characteristics that may represent exclusion criteria from $\mathrm{NC}$, such as performance status, renal function, patients willingness to undergo $\mathrm{NC}$, or physician interest in recommending NC prior to RC were not available. Fourth, it is of note that the exact timing of RT administration was not established. It might be postulated that the majority of such patients received this treatment modality after RC. Last, but not least, our study relies on patients older than 65 years. 
Schiffmann et al.

Consequently, our findings might not be generalizable to younger individuals.

In conclusion, we reported lower than anticipated overall $(6.4 \%)$ use of NC during the study period. Nonetheless, the rate increased from $6.1 \%$ (1991) to $15.0 \%$ (2009). Older and unmarried individuals were less likely to receive NC. Finally, NC rates were higher in T2 UCUB patients. Some of the observed discrepancies, such as lower use in unmarried individuals, may require correction. Better adherence to guidelines should be encouraged and implemented, especially based on the confirmed benefits of $\mathrm{NC}$ according to randomized, controlled trials.

Competing interests: The authors declare no competing financial or personal interests.

This paper has been peer-reviewed.

\section{References}

1. Siegel R, Naishadham D, Jemal A. Cancer statistics, 2013. Ca Cancer J Clin 2013; 63:11-30. http://dx.doi.org/10.3322/caac.21166

2. Howlader NA, Krapcho M, Garshell J, et al (eds). SEER Cancer Statistics Review, 1975-2010. National Cancer Institute Bethesda, MD, http://seercancergov/csr/1975_2010/, based on November 2012 SEER data submission, posted to the SEER web site, April 2013. Accessed February 1, 2016.

3. Stenzl A, Cowan NC, De Santis M, et al. Treatment of muscle-invasive and metastatic bladder cancer: Update of the EAU guidelines. Eur Urol 2011;59:1009-18. http://dx.doi.org/10.1016/i.eururo.2011.03.023

4. Clark PE, Agarwal N, Biagioli MC, et al. Bladder cancer. J Natl Compr Canc Netw 2013;11:446-75.

5. Grossman $H B$, Natale RB, Tangen $C M$, et al. Neoadjuvant chemotherapy plus cystectomy compared with cystectomy alone for locally advanced bladder cancer. N Engl J Med 2003;349:859-66. http://dx.doi. org/10.1056/NEJMoa022148

6. Sternberg CN, Bellmunt J, Sonpavde G, et al. ICUD-EAU International Consultation on Bladder Cancer 2012: Chemotherapy for urothelial carcinoma-neoadjuvant and adjuvant settings. Eur Urol 2013;63:58-66. http://dx.doi.org/10.1016/i.eururo.2012.08.010

7. Neoadjuvant chemotherapy in invasive bladder cancer: Update of a systematic review and meta-analysis of individual patient data advanced bladder cancer (ABC) meta-analysis collaboration. Eur Urol 2005;48: 202-5;discussion 205-6. http://dx.doi.org/10.1016/..eururo.2005.04.006
8. Porter MP, Kerrigan MC, Donato BM, et al. Patterns of use of systemic chemotherapy for Medicare beneficiaries with urothelial bladder cancer. Urol Oncol 2011;29:252-8. http://dx.doi.org/10.1016/i. urolonc.2009.03.021

9. Zaid HB, Patel SG, Stimson CJ, et al. Trends in the utilization of neoadiuvant chemotherapy in muscleinvasive bladder cancer: Results from the National Cancer Database. Urology 2014;83(1):75-80. http:// dx.doi.org/10.1016/i.urology.2013.07.072

10. Warren JL, Klabunde CN, Schrag D, et al. Overview of the SEER-Medicare data: Content, research applications, and generalizability to the United States elderly population. Medical Care 2002;40:IV3-18. http:// dx.doi.org/10.1097/00005650-200208001-00002

11. Klabunde CN, Potosky AL, Legler JM, et al.Development of a comorbidity index using physician claims data. J Clin Epidemiol 2000;53:1258-67. http://dx.doi.org/10.1016/S0895-4356(00)00256-0

12. Singh GK and National Cancer Institute (U.S.). Area socioeconomic variations in U.S. cancer incidence, mortality, stage, treatment, and survival, 1975-1999. Bethesda, MD, U.S. Dept. of Health and Human Services, National Institutes of Health, National Cancer Institute, 2003. Available at http://open-dev. umms.med.umich.edu/sites/default/files/1232/reading-resources-1/Singh-fullarticle.pdf. Accessed February 8, 2016.

13. Thompson RH, Boorijan SA, Kim SP, et al. Eligibility for neoadjuvant/adjuvant cisplatin-based chemotherapy among radical cystectomy patients. BJU Int 2014;113:E17-21. http://dx.doi.org/10.1111/bju.12274

14. Hollenbeck BK, Miller DC, Taub D, et al. Aggressive treatment for bladder cancer is associated with improved overall survival among patients 80 years old or older. Urology 2004;64: 292-7. http://dx.doi. org/10.1016/i.urology.2004.03.034

15. Bamias A, Efstathiou E, Moulopoulos LA, et al. The outcome of elderly patients with advanced urothelial carcinoma after platinum-based combination chemotherapy. Ann Oncol 2005; 16: 307-13. http://dx.doi. org/10.1093/annonc/mdi039

16. Bianchi $M$, Becker $A$, Abdollah $F$, et al. Rates of open versus laparoscopic and partial versus radical nephrectomy for Tla renal cell carcinoma: A population-based evaluation. Int J Urol 2013;20:1064-71 http://dx.doi.org/10.1111/iju.12110

17. Denberg TD, Beaty BL, Kim FJ, et al. Marriage and ethnicity predict treatment in localized prostate carcinoma. Cancer 2005; 103:1819-25. http://dx.doi.org/10.1002/cncr.20982

18. Chang SS, Hassan JM, Cookson MS, et al. Delaying radical cystectomy for muscle invasive bladder cancer results in worse pathological stage. J Urol 2003;170:1085-7. http://dx.doi.org/10.1097/01. ju.0000086828.26001.c0

19. Gotto GT, Shea-Budgell MA, Rose MS, et al. Predictors of referral for neoadjuvant chemotherapy prior to radical cystectomy for muscle-invasive bladder cancer and changes in practice over time. Can Urol Assoc J 2015;9:236-41. http://dx.doi.org/10.5489/cuai.2722

Correspondence: Dr. Jonas Schiffmann, Martini-Clinic, Prostate Cancer Centre, University Medical Centre Hamburg-Eppendorf, Germany; i.schiffmann@klinikum-braunschweig.de 